\title{
PRODUÇÃO DE MATERIA SECA E INDICE DE ÁREA FOLIAR DE FORRAGEIRAS EM DIFERENTES MANEJOS DO SOLO
}

\author{
Edney Leandro da Vitória ${ }^{2}$, Haroldo Carlos Fernandes ${ }^{3}$, Mauri Martins Teixeira ${ }^{4}$, Paulo Roberto Cecon $^{5}$
}

\section{RESUMO}

O manejo do solo inadequado, aliado a uma baixa fertilidade do mesmo, constitui um dos principais fatores limitantes da produção pecuária nas regiões tropicais. No segundo semestre do ano de 2009, na área experimental do IFES de Santa Teresa, no estado do Espírito Santo, foi analisada a produtividade de forrageiras em três sistemas de manejo do solo: preparo convencional, cultivo mínimo e plantio direto. O objetivo foi estudar a influência de sistemas de manejo do solo sobre a produtividade de forrageiras em termos de produção de matéria seca. O experimento foi instalado em esquema de parcela sub-subdividida no delineamento em blocos casualizados com quatro repetições. Somente o manejo do solo, o período e a interação entre período e a forrageira apresentaram diferença considerada significativa $(\mathrm{p}<0,05)$ em relação à produção de matéria seca e índice de área foliar. Porém, estatisticamente o manejo do solo não apresentou diferença significativa na interação com o tipo de forrageira. Os sistemas de manejo do solo utilizados influenciam na produção de matéria seca, independente da forrageira, sendo que o preparo convencional apresentou melhores resultados.

Palavras-Chave: preparo do solo, forragicultura, propriedades físicas do solo

\section{ABSTRACT \\ DRY MATTER YIELD AND LEAF AREA INDEX OF FORAGE CROPS UNDER DIFFERENT SOIL MANAGEMENT}

The inadequate soil management, combined with low soil fertility, is one of the limiting factors in cattle production in tropical regions. In the second half of 2009, the experimental area of the IFES of Santa Teresa, Espírito Santo state, Brazil, was analyzed for forage yield in three soil management systems to determine their influence on dry matter yield. The experiment was installed sub-split-plot randomized block design with four replications. The soil management, the period and the interaction between period and forage crop showed significant $(p<0.05)$ difference regarding dry matter yield and leaf area index. However soil management interaction with forage crop was not significant. The management systems influenced dry matter yield, independent of the forage crop, with the conventional preparation having the most yields.

Keywords: soil management, crop forage, soil physical attributes

\section{Recebido para publicação em 15/07/2011. Aprovado em 20/04/2012.}

1- Parte da dissertação de Doutorado do primeiro autor

2- Engenheiro Agrícola, Professor Adjunto do DCAB/CEUNES/UFES, São Mateus-ES, edney.vitoria@ceunes.ufes.br

3- Engenheiro Agrícola, Professor Associado do DEA/UFV, Viçosa-MG, Haroldo@ufv.br

4- Engenheiro Agrônomo, Professor Associado dop DEA/UFV, Viçosa-MG, Mauri@ufv.br

5- Engenheiro Agrônomo, Professor Associado do DET/UFV, Viçosa-MG, cecon@ufv.br 


\section{INTRODUÇÃO}

Nos últimos anos o elevado potencial de produção das pastagens tropicais tem sido ressaltado e justificado pela disponibilidade de espécies forrageiras extremamente produtivas e adaptadas ao pastejo, como é o caso dos capins dos gêneros Brachiaria e Panicum. De fato, essas espécies predominam nas áreas de pastagens do País e, sem dúvida, representam boa parte dos esforços e dos recursos investidos em programas de pesquisa, melhoramento e introdução de novas espécies e cultivares. No entanto, em termos práticos, os benefícios desse potencial de produção dificilmente têm sido realizados, uma vez que os indicadores produtivos e zootécnicos apontam para aumentos de produtividade muito modestos em relação ao que poderia ser obtido (NASCIMENTO JÚNIOR et al., 2004).

As plantas do gênero Brachiaria são caracterizadas pela sua grande flexibilidade de uso e manejo, sendo tolerantes a uma série de limitações e, ou, condições restritivas de utilização para um grande número de espécies forrageiras. Dentre as braquiárias, a Bracharia brizantha cv Marandu (capim-Marandu) adquiriu grande expressividade nas áreas de pastagens cultivadas e, por essa razão, tornou-se uma das plantas forrageiras mais detalhadamente estudadas no meio científico nacional (DA SILVA; CORSI, 2003; GONÇALVES, 2002).

As plantas do gênero Panicum são caracterizadas pelo seu grande potencial de produção de forragem sendo, porém, menos flexíveis que plantas como as do gênero Brachiaria, por apresentarem limitações e, ou, dificuldades para serem manejadas sob lotação contínua, prevalecendo, de uma forma geral, o seu uso na forma de pastejo rotacionado. Dentre os diversos cultivares, Panicum maximum cv Mombaça (capim-Mombaça) e cv Tanzânia (capim-Tanzânia) adquiriram grande destaque nas áreas de pastagens cultivadas do país e, por essa razão, têm concentrado boa parte dos esforços e recursos investidos em pesquisa em anos recentes (BARBOSA, 2004).

O sistema de manejo do solo com grade aradora tem sido o mais usado na implantação de forrageiras. Normalmente, a grade trabalha o solo a pouca profundidade e apresenta alto rendimento de campo. Porém, o uso contínuo desse implemento pode levar à formação de camadas compactadas, chamadas "pé- de-grade" (SILVA, 1992). O arado de aiveca é pouco usado porque requer maior tempo e energia para a sua operação que os demais implementos, embora se tenha obtido maior produtividade de milho, de soja e de trigo (KLUTHCOUSKI et al., 2000) quando comparado com o plantio direto ou com o preparo com grade aradora, que ocorreu devido ao pior desenvolvimento do sistema radicular nesses sistemas de manejo, por causa da compactação do solo na camada superficial ou subsuperficial, respectivamente.

O plantio direto pode ser alternativa ao sistema convencional de preparo do solo e contribuir para a sustentabilidade de sistemas agrícolas intensivos, por manter o solo coberto por restos culturais ou por plantas vivas o ano inteiro, minimizando os efeitos da erosão e, ainda, manter o conteúdo de matéria orgânica (ALBUQUERQUE et al., 2001).

Em condições de plantio direto estabilizado, maiores produtividades de forrageiras, de milho, de soja e de trigo foram obtidas em relação aos manejos que mobilizavam mais o solo (SANTOS et al., 2006).

Verifica-se que, para algumas culturas, o preparo mínimo do solo propicia maiores produções em comparação com o convencional. No entanto, são as avaliações de efeitos dos sistemas de manejo do solo (FALLEIRO et al., 2003).

Estudando dois tipos de forrageiras, Bowman et al. (2008) verificaram que maior produção de biomassa para o Andropogon gayanus e Brachiaria brizantha foi obtida no manejo do solo com grade aradora+arado de discos e grade aradora, respectivamente, sendo que os sistemas de manejo do solo entre as espécies Andropogon gayanus e Brachiaria brizantha brizantha diferiram na produção de biomassa, apenas na terceira semana de avaliação.

Analisando três sistemas de manejo do solo em termos de produtividade da Panicum maximum, Valência et al. (2008) verificaram que o plantio direto proporcionou um rendimento $17 \%$ superior em relação ao manejo que utilizou somente grades pesada e leve, notando-se que práticas conservacionistas, que utilizaram o escarificador e o plantio direto, proporcionaram aumentos na sua produtividade com o decorrer do tempo.

Neste contexto, o sistema de manejo do solo pode influenciar a produtividade e o índice de área foliar (IAF) de forrageiras. O objetivo deste trabalho foi verificar se o manejo do solo tem influência na

\section{REVENG}


produtividade das forrageiras (capim-brachiaria e capim-mombaça) em termos de produção de biomassa e IAF.

\section{MATERIAL E MÉTODOS}

Este trabalho foi realizado na área experimental do Instituto Federal de Ensino Superior (IFES), Campus de Santa Teresa, localizada no município de Santa Teresa, região Serrana do Espírito Santo, situado entre as coordenadas $19^{\circ} 48^{\prime} 36^{\prime \prime}$ de latitude sul e $40^{\circ} 40^{\prime} 48^{\prime}$ "de longitude oeste de Greenwich, e altitude média de $150 \mathrm{~m}$. O clima da região é temperado úmido com inverno seco e verão quente, Cwa, segundo a classificação de Köppen e Geiger (1928). A média de temperatura nos meses mais quentes está entre 27,8 e $30,7^{\circ} \mathrm{C}$ e a dos meses mais frios entre 9,4 e $11,8^{\circ} \mathrm{C}$, com temperatura média anual entre 16 e $18^{\circ} \mathrm{C}$. O índice pluviométrico para a área experimental é superior a $1.800 \mathrm{~mm}$ anuais. $\mathrm{O}$ solo é classificado como Latossolo Amarelo eutrófico, textura arenosa, com $300 \mathrm{~g} \mathrm{~kg}^{-1}$ de argila, $70 \mathrm{~g} \mathrm{~kg}^{-1}$ de silte e $630 \mathrm{~g} \mathrm{~kg}^{-1}$ de areia, conforme Neiro (2002).

A área experimental foi cultivada nos cinco anos anteriores à implantação do experimento, em um sistema de preparo conservacionista, rotação de cultura e preparo mínimo do solo, com as culturas de sorgo (Sorghum bicolor) e colonião (Panicum maximum). As adubações para as culturas foram realizadas conforme recomendações técnicas baseadas em análises de solo.

Para a caracterização do solo da área experimental, as variáveis quantificadas foram a densidade do solo (Ds), a porosidade total (Pt), o volume de macroporos (Mac), o volume de microporos (Mic) e a resistência do solo à penetração $(\mathrm{Rp})$, além da umidade gravimétrica do solo (Ug). A densidade e a umidade gravimétrica do solo foram determinadas no Laboratório de Física do Solo do IFES, Campus Santa Teresa-ES; a porosidade total, volume de macroporos e microporos foram determinadas no Laboratório de Física do Solo da Universidade Federal de Viçosa, Viçosa, MG.

Para análise da densidade do solo foram coletadas amostras indeformadas por meio do método do anel volumétrico de Uhland, em camadas do perfil do solo, 0 - 0,15 m e 0,15-0,30 m, utilizando-se os pontos de cruzamento em uma malha regular com espaçamento $5 \mathrm{~m}$ x $5 \mathrm{~m}$, resultando em 99 pontos de coleta numa área de $2000 \mathrm{~m}^{2}$. Após a coleta, as amostras foram colocadas em estufa durante 24 horas, a $105^{\circ} \mathrm{C}$. A densidade do solo foi determinada utilizando a seguinte expressão:

$$
\mathrm{Ds}=\frac{\mathrm{Ms}}{\mathrm{Va}}
$$

em que

Ds $=$ densidade do solo $\left(\mathrm{kg} \mathrm{dm}^{-3}\right)$;

$\mathrm{MS}=$ massa do solo secado em estufa a $105^{\circ} \mathrm{C}$; e

$\mathrm{Va}=$ volume do anel $\left(\mathrm{cm}^{3}\right)$.

A porosidade foi determinada pelo método indireto:

$\mathrm{Pt}=\left(1-\frac{\mathrm{Ds}}{\mathrm{Dp}}\right) \times 100$

em que

$\mathrm{Pt}=$ porosidade total $(\%)$;

Ds = densidade do solo $\left(\mathrm{kg} \mathrm{dm}^{-3}\right) ; \mathrm{e}$

$\mathrm{Dp}=$ densidade das partículas $\left(\mathrm{kg} \mathrm{dm}^{-3}\right)$.

A densidade das partículas foi determinada pelo método do balão volumétrico e o volume de microporos foi determinado pelo método da mesa de tensão (EMBRAPA, 1999). O volume de macroporos foi determinado pelo método indireto:

$M a c=P-M i c$

em que

Mac $=$ volume de macroporos $\left(\mathrm{m}^{3} \cdot \mathrm{m}^{-3}\right) ;$

Mic $=$ volume de microporos $\left(\mathrm{m}^{3} \cdot \mathrm{m}^{-3}\right)$.

A resistência do solo à penetração foi determinada por meio de um penetrômetro marca DLG, modelo PNT-2000, com uma haste de $600 \mathrm{~mm}$ de comprimento, $9,53 \mathrm{~mm}$ de diâmetro, equipada com um cone de 129,3 $\mathrm{mm}^{2}$ de área da base, 12,83 $\mathrm{mm}$ de diâmetro e 30 graus de ângulo sólido. Foram determinados nos pontos de cruzamento das coordenadas X, Y como local de amostragem. A 
resistência do solo à penetração foi expressa através do índice de cone (IC), nos intervalos de 0 - 0,15 m e $0,15-0,30 \mathrm{~m}$, conforme metodologia da ASAE S 313, citada por Balastreire (1987).

Para a determinação do teor de água no solo utilizou-se o método padrão de estufa, seguindo a metodologia da Empresa Brasileira de Pesquisa Agropecuária - EMBRAPA (1999). As amostras foram coletadas nos pontos de cruzamento das coordenadas X, Y como local de amostragem.

O Quadro 2 apresenta as características das máquinas e implementos utilizados nas operações de cultivo, manejo do solo e plantio.

Oexperimento foi instalado emblocos casualizados em esquema de parcela sub-subdividida, sendo as parcelas constituídas pelos três sistemas de manejo do solo (preparo convencional, cultivo mínimo e plantio direto); as subparcelas constituídas por duas forrageiras (Brachiaria brizantha e mombaça); e as sub-subparcelas por cinco períodos de avaliação de produtividade (30, 45, 60, 75 e 90 dias após plantio), com quatro repetições. As unidades experimentais tinham $6 \mathrm{~m}$ de largura e $20 \mathrm{~m}$ de comprimento, espaçadas três metros entre si.

Aplicou-se a dose de 3,0 $\mathrm{L} \mathrm{ha}^{-1}$ de Glifosato Potássico para dessecação pré-semeadura na área de aproximadamente 0,5 ha, onde o experimento foi implantado. 15 dias após a aplicação, com a palhada completamente seca e acamada sobre o solo, o experimento de campo foi implantado.

O manejo de solo convencional (PC) foi feito com uma passada do arado de discos, com objetivo de revolver a leiva do solo e incorporar o resto de cultura e palhada dessecada, seguida de duas passadas com a grade niveladora para nivelar o solo e destorroá-lo ao ponto de receber as sementes das forrageiras.

Para o cultivo mínimo (CM) utilizou-se uma passada do cultivador com hastes espaçadas de 0,20 $\mathrm{m}$, o mesmo espaçamento utilizado na semeadura das forrageiras com intuito que as sementes fossem depositadas apenas no local onde o solo foi trabalhado.

No plantio direto (PD) as sementes das forrageiras foram depositadas diretamente sobre a palhada dessecada, utilizando-se uma semeadora-adubadora específica para esta finalidade, conforme Figura 4. A semeadora-adubadora foi regulada para um espaçamento entre linhas de $0,20 \mathrm{~m}$ e as sementes foram depositadas no solo em uma profundidade média de $0,02 \mathrm{~m}$, tanto para capim-brachiaria quanto para o capim-mombaça.

As variáveis de produtividade analisadas foram matéria seca total (MS) e IAF avaliados em cada um dos períodos após o plantio, ou seja, 30, 45, 60, 75 e 90 dias. Para determinação da produção de matéria seca, as forrageiras foram cortadas, em média, a 0,10 $\mathrm{m}$ do solo. $\mathrm{O}$ corte foi feito em pontos aleatórios em cada unidade experimental, utilizando-se um gabarito de $1 \mathrm{~m}^{2}(1 \mathrm{x} 1 \mathrm{~m})$. O material foi colocado em saco

Quadro 2. Especificações técnicas das máquinas e implementos utilizados

Máquina e, ou, implemento

Trator

Arado de discos

Grade niveladora

Escarificador

Pulverizador

Semeadora
Especificações técnicas

Marca New Holland, modelo TL 85 E, tração dianteira auxiliar; motor MWM, potência de $83 \mathrm{cv}$ a $2400 \mathrm{rpm}$; turbo aspirado.

Marca Baldan, reversível modelo AR-PR; largura de corte de 800 a 900 mm; três discos de 28 polegadas, massa total $560 \mathrm{~kg}$.

Marca Baldan, tipo offset, modelo NV; largura de trabalho $2.350 \mathrm{~mm} ; 28$ discos de 20 polegadas, massa total $630 \mathrm{~kg}$.

Marca Super Tatu, modelo CE; 9 hastes, comprimento do chassis de $2.800 \mathrm{~mm}$; massa total $188 \mathrm{~kg}$.

Marca Jacto, modelo JP-402-A; pressão máxima da bomba $21 \mathrm{kgf} \mathrm{cm}^{-2}$ a $540 \mathrm{rpm}$; comprimento da barra de pulverização de $10 \mathrm{~m}$; distância entre bicos de $0,50 \mathrm{~m}$; bicos de jato plano.

Marca Semeato, plantio direto, modelo SHMA/11; 11 linhas; capacidade do depósito de sementes de $38 \mathrm{~L}$, capacidade do depósito de fertilizante de $366 \mathrm{~L}$. 
de papel identificado, pesado e levado à estufa de ventilação forçada, às temperaturas entre 58 e $65^{\circ} \mathrm{C}$ para determinação de sua matéria seca e estimativa da produção de MS.

O IAF foi determinado indiretamente com aparelho analisador (ceptômetro) de dossel AccuPAR, modelo LP-80. As medições foram realizadas a partir de uma leitura de referencia sobre o dossel forrageiro e uma das leituras feitas abaixo do dossel (no nível do solo). As medições foram realizadas sempre ao amanhecer, evitando uma superestimativa recorrente da elevada radiação, transmitida pelas folhas quando a luz incide diretamente sobre as mesmas. Em cada unidade experimental foram realizadas 10 leituras acima e 10 leituras abaixo do dossel. A partir destas leituras, o aparelho estimou o IAF por meio de equações matemáticas (WELLES, 1991).

Os efeitos dos sistemas de manejo do solo sobre a produtividade das forrageiras foram interpretados por meio de análise de variância, segundo o delineamento de blocos casualizados. A diferença entre médias dos tratamentos foi avaliada pelo teste de Tukey, considerando uma significância de $5 \%$. Com a finalidade de ajustar as curvas de produtividade nos diferentes períodos avaliados, foi realizada a análise de regressão. Os modelos foram escolhidos com base na significância dos coeficientes de regressão e coeficiente de determinação, utilizando o Statistical Analysis System (SAS INSTITUTE, 2002) e Sistema para Análises Estatísticas (UNIVERSIDADE FEDERAL DE VIÇOSA - UFV, 2007), considerando um nível de significância igual a $5 \%$.

\section{RESULTADOS E DISCUSSÃO}

Nos resultados apresentados no Quadro 3 verificase que somente o manejo do solo, o período e a interação entre período e a forrageira apresentaram diferença considerada significativa $(p<0,05)$ em relação à produção de matéria seca e IAF. Porém, estatisticamente, o manejo do solo não apresentou diferença significativa $(p>0,05)$ na interação com espécie forrageira. $\mathrm{O}$ fato de não ter ocorrido interação significativa entre os sistemas de manejo do solo, período e forrageira na resposta de matéria seca e IAF pode ser explicado pelo manejo adequado do solo na área experimental nos períodos anteriores a implantação do experimento. Brustolin et al. (2001), Leite (2002) e Silva (2003) não obtiveram diferenças significativas $(p>0,05)$ na produtividade do milho forrageiro em função do manejo do solo e do espaçamento entre linhas de plantio.

Quadro 3. Resumo da análise de variância da matéria seca e IAF para os fatores analisados e as diferentes interações

Fonte de variação Graus de liberdade

$\begin{array}{lc}\text { Bloco } & 3 \\ \text { Preparo (P) } & 2 \\ \text { Erro A } & 6 \\ \text { Forrageira (F) } & 1 \\ \text { P x F } & 2 \\ \text { Erro B } & 9 \\ \text { Período (PER) } & 4 \\ \text { PER x P } & 8 \\ \text { PER x F } & 4 \\ \text { PER X P X F } & 8 \\ \text { Resíduo } & 120 \\ \text { CV (\%) } & \end{array}$

\section{Sistema de manejo (P)}

Preparo convencional

Cultivo mínimo

Plantio direto

\begin{tabular}{cc} 
MS & IAF \\
\hline \multicolumn{2}{c}{ Quadrado médio } \\
$58.959,3^{*}$ & $0,22^{*}$ \\
$93.036,1^{*}$ & $1,79^{*}$ \\
$12.887,3$ & 0,03 \\
$8.217 .620,0^{\text {ns }}$ & $6,12^{\text {ns }}$ \\
$135,4^{\text {ns }}$ & $0,05^{\text {ns }}$ \\
$4.806,9$ & 0,046 \\
$0,00^{*}$ & $90,69^{*}$ \\
$3.440,99^{\text {ns }}$ & $0,052^{\text {ns }}$ \\
$1.009572,0^{*}$ & $0,33^{*}$ \\
$3.619,0^{\text {ns }}$ & $0,039^{\text {ns }}$ \\
8635,8 & 0,043 \\
3,54 & 5,64
\end{tabular}

$\begin{array}{ll}2.671,9 \mathrm{a} & 3,87 \mathrm{a} \\ 2.609,6 \mathrm{~b} & 3,69 \mathrm{~b} \\ 2.598,6 \mathrm{~b} & 3,52 \mathrm{c}\end{array}$

Em cada coluna para cada fator, médias seguidas de mesmas letras minúsculas não diferem entre si, pelo Teste de Tukey, a $5 \%$ de probabilidade. ns: não significativo $(\mathrm{p}>0,05) ;{ }^{*}$ significativo $(\mathrm{p} \leq 0,05)$. 
Estudando sistemas de manejo do solo na cultura de milho, Marques (2002) e Silva (2003), não encontraram nenhuma influência destes na produtividade. Moreira Filho et al. (2008), em estudo sobre o crescimento vegetativo do capimmombaça submetido a diferentes manejos do solo, não encontraram diferenças significativas $(\mathrm{p}>$ $0,05)$ no acúmulo de matéria seca, altura de corte e IAF. Cruz et al. (2009) estudaram o consórcio de milho com Brachiaria brizantha e concluíram que a semeadura direta e o cultivo mínimo não proporcionaram diferenças significativas entre si, contudo apresentaram resultados inferiores ao do sistema convencional. Aguiar et al. (2004), Pequeno (2006) e Benett (2008) concluíram que o acúmulo de matéria seca e o IAF em forrageiras depende da adubação, da fertilidade do solo, da disponibilidade de água e, em menor grau, do sistema de manejo do solo.

Os resultados médios de produção de matéria seca e de IAF das forrageiras submetidas ao preparo convencional foram significativamente maiores do que os encontrados para o cultivo mínimo e para o plantio direto, o que pode ser explicado pelo fato da quebra da camada compactada na superfície, propiciando o melhor contato das sementes com solo. Conclusão semelhante a essa foi apresentada por Kluthcouski et al. (2000) que constataram a indução de maiores produtividades sob preparo convencional, nos primeiros anos de produção. A produção de matéria seca e o IAF maiores, registrados no preparo convencional e no cultivo mínimo, quando comparados ao plantio direto, também pode estar relacionados à maior mineralização da matéria orgânica nos primeiros manejos. Isto pela mobilização do solo, o que gera maior nitrogênio disponível para as culturas. $\mathrm{O}$ rendimento menor das forrageiras sob plantio direto pode ser atribuído à formação de camadas compactadas induzidas por esse sistema de manejo, principalmente próximo a superfície do solo, fato observado por Suzuki et al. (2004).

A matéria seca e o IAF apresentaram diferenças significativas em função do período da avaliação e da forrageira, embora o sistema de manejo do solo não tenha manifestado diferenças quando sob efeito da interação com a forrageira. Observou-se melhor resultado de campo do preparo convencional por proporcionar maiores produtividades tanto para o capim braquiária como para o capim-mombaça. O Quadro 4 apresenta os resultados de produção de matéria seca e de IAF em função do período pós plantio 30 dias após a semeadura não se observou diferença entre a produção de matéria seca entre o capim braquiária e o capim-mombaça, o que pode ser explicado pelo fato do sistema radicular das forrageiras serem semelhantes nos primeiros 30 dias. Nos demais períodos, a produção de matéria seca do capim-mombaça foi significativamente superior ao do capim braquiária. Em relação ao IAF, não se observou diferença significativa ( $p$ $>0,05)$ entre as forrageiras, porém a diferença é significativa quando comparadas por período.

Quadro 4. Matéria seca e IAF em função do período após semeadura e forrageir

\begin{tabular}{ccccccc}
\hline \multirow{2}{*}{ Parâmetro avaliado } & Forrageira & \multicolumn{5}{c}{ Período após a semeadura (dias) } \\
\cline { 3 - 7 } & Brachiaria & 30 & 45 & 60 & 75 & 90 \\
\hline \multirow{2}{*}{ Matéria seca $\left(\mathrm{kg} \mathrm{ha}^{-1}\right)$} & brizantha & $605,6 \mathrm{aA}$ & $915,2 \mathrm{aB}$ & $1736,1 \mathrm{aC}$ & $3910,6 \mathrm{aD}$ & $\begin{array}{c}4897,1 \\
\mathrm{aE}\end{array}$ \\
& Mombaça & $652,8 \mathrm{aA}$ & $\begin{array}{c}1111,7 \\
\mathrm{bB}\end{array}$ & $\begin{array}{c}2079,1 \\
\mathrm{bC}\end{array}$ & $\begin{array}{c}4717,6 \\
\mathrm{bD}\end{array}$ & $\begin{array}{c}5640,1 \\
\mathrm{bE}\end{array}$ \\
& & & & & & \\
Índice de área foliar & $\begin{array}{c}\text { Brachiaria } \\
\text { brizantha }\end{array}$ & $1,31 \mathrm{aA}$ & $2,64 \mathrm{aB}$ & $3,74 \mathrm{aC}$ & $4,78 \mathrm{aD}$ & $5,01 \mathrm{aE}$ \\
& Mombaça & $1,41 \mathrm{aA}$ & $3,25 \mathrm{aB}$ & $4,20 \mathrm{aC}$ & $5,15 \mathrm{aD}$ & $5,39 \mathrm{aE}$
\end{tabular}

Médias seguidas pela mesma letra minúscula na coluna e mesma letra maiúscula na linha não apresentam diferenças significativas entre si, considerando um nível de $5 \%$ de probabilidade pelo teste de Tukey. 
A análise de regressão permitiu a obtenção do modelo explanatório "raiz quadrada" que demonstra a tendência do acúmulo de matéria seca e IAF durante o período do experimento (Figuras 6a e 6b).

As taxas de acúmulo em matéria seca superam aquelas obtidas por diversos autores citados por Miller et al. (2002): Bryan e Sharpe (1965) obtiveram 2,24 $\mathrm{kg} \mathrm{ha}^{-1} \mathrm{dia}^{-1}$ para o capim Pangola (Digitaria decumbens Stent); Singh e Chatterjee (1968) reportaram taxas de 7,0; 5,4 e $1,1 \mathrm{~kg}$ ha $^{-1}$ dia $^{-1}$ para os capins Brachiaria brizantha, Andropogon gayanus e Paspalum notatum, respectivamente; Pedreira (1973) obteve, para o capim Colonião, taxas de 2,0; 3,6 e $8,7 \mathrm{~kg} \mathrm{ha}^{-1}$ dia $^{-1}$, nos meses de julho, agosto e setembro, respectivamente; enquanto Pedreira (1979), ainda para o capim Colonião, reporta taxas de 1,$7 ; 7 ; 12,2 ; 22,3$ e $39,6 \mathrm{~kg} \mathrm{ha}^{-1} \mathrm{dia}^{-1}$, nos meses de agosto, setembro, outubro, novembro e dezembro, respectivamente.

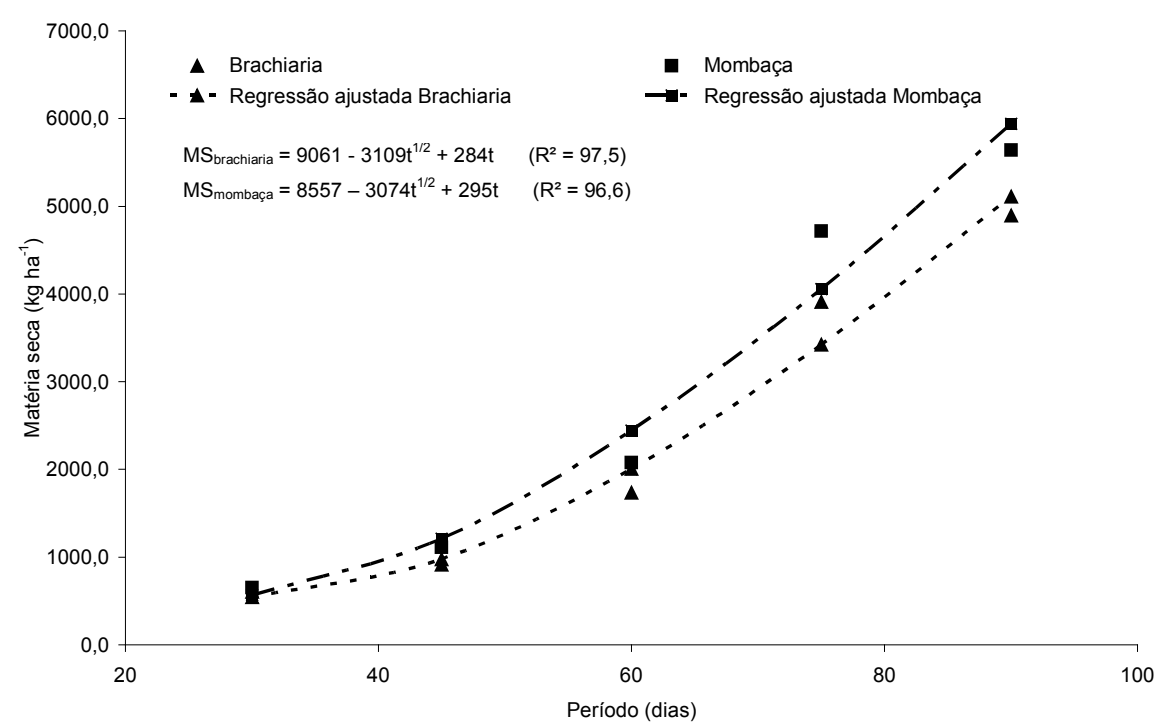

(a)

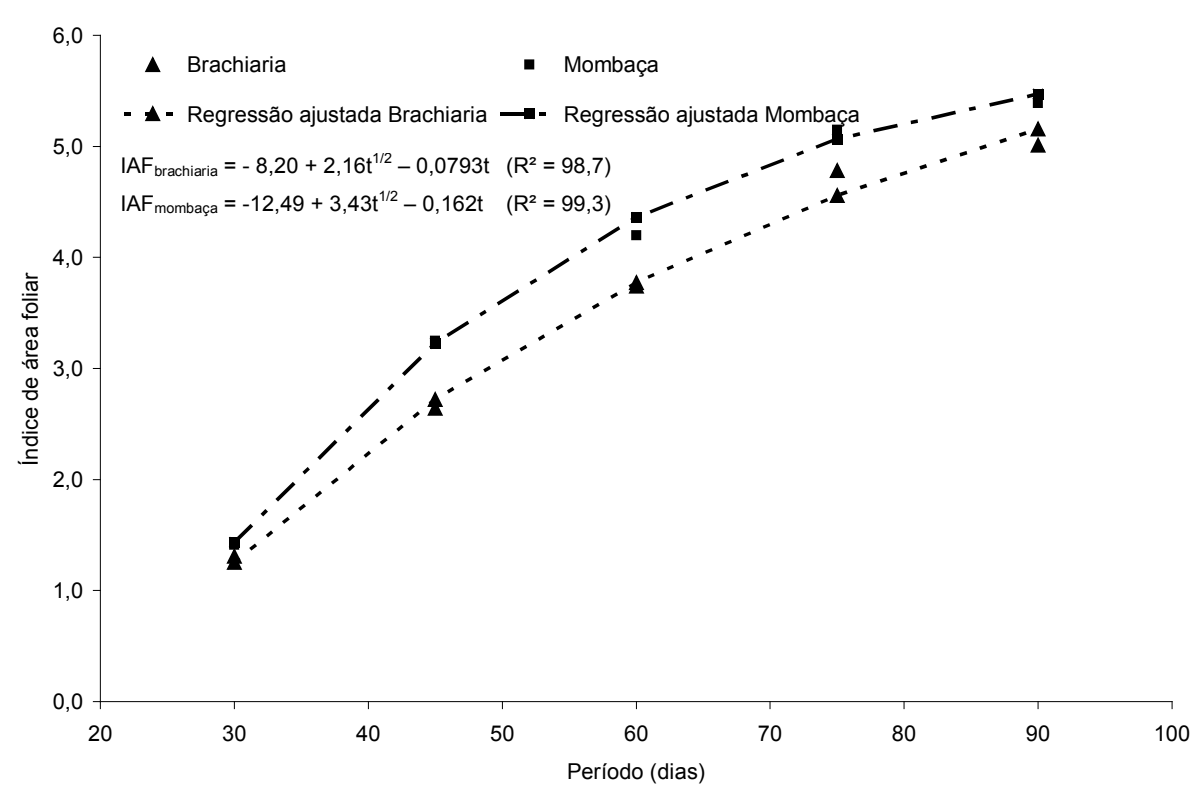

(b)

Figura 6. Produção de matéria seca (a) e IAF (b) para a capim-brachiaria e capim-mombaça em função do período (dias) após semeadura. 


\section{CONCLUSÕES}

- Os sistemas de manejo do solo utilizados influenciam na produção de matéria seca e no $\mathrm{IAF}$, independente da forrageira;

- O preparo convencional proporcionou maiores produções de biomassa e de IAF quando comparado ao cultivo mínimo e o plantio direto; e

- O manejo do solo não pode ser considerado isoladamente como fator relevante na produção de matéria seca e de IAF.

\section{AGRADECIMENTOS}

Ao Conselho Nacional de Desenvolvimento Científico e Tecnológico (CNPq) e à Fundação de Amparo a Pesquisa de Minas Gerais (FAPEMIG).

\section{REFERÊNCIAS BIBLIOGRÁFICAS}

AGUIAR, A.P.A. et al. Crescimento de uma pastagem de capim braquiarão (Brachiaria brizantha brizantha cv marandu) irrigada e manejada intensivamente. In: REUNIÃO ANUAL DA SOCIEDADE BRASILEIRA DE ZOOTECNIA, 41., 2004, Campo Grande. CD-ROM... Campo Grande: SBZ, 2004.

ALBUQUERQUE, J.A. et al. Efeitos da integração lavoura-pecuária nas propriedades físicas do solo e características da cultura do milho. R. Bras. Ci. Solo, Viçosa, v. 25, p. 717-723, 2001.

BALASTREIRE, L.A. Máquinas agrícolas. 1 Ed. São Paulo: Manole, 1987. 307 p.

BARBOSA, R.A. Características morfofisiológicas e acúmulo de forragem em capim-Tanzânia (Panicum maximum Jacq. cv. Tanzânia) submetido a freqüências e intensidades de pastejo. 2004. 122p. Tese (Doutorado em Zootecnia) Universidade Federal de Viçosa, Viçosa, MG. 2004.

BENETT, C.G.S. Resposta da Brachiaria brizantha brizantha cv. Marandu a diferentes tipos de adubação. Revista de Ciências Agro-Ambientais, Alta Floresta, v. 6, n. 1, p. 13- 20, 2008.
BOWMAN, M.T.; BECK, P.A.; WATKINS, K.B.; ANDERS, M.M.; GADBERRY, M.S.; LUSBY, K.S.; GUNTER, S.A.; HUBBELL, D.S. Tillage systems for production of small-grain pasture. Agronomy Journal, Madisson, v. 100, p. 1289-1295, 2008.

BRUSTOLIN, R. et al. Desenvolvimento e rendimento do milho safrinha cultivando em diferentes espaçamentos entre linhas. In: CONGRESSO BRASILEIRO DE ENGENHARIA AGRICOLA, 30., 2001, Foz do Iguaçu. CDROM... Foz do Iguaçu: Sociedade Brasileira de Engenharia Agrícola, 2001.

CRUZ, S.C.S ; PEREIRA, F. R. S. ; BICUDO, S. J. ; SANTOS, J. R. ; ALBUQUERQUE, A. W. ; MACHADO, C. G. . Consórcio de milho e Brachiaria brizantha decumbens em diferentes preparos de solo. Acta Scientiarum. Agronomy, Maringá, v. 31, n. 4, p. 633-639, 2009.

DA SILVA, S.C.; CORSI, M. Manejo do pastejo. In: SIMPÓSIO SOBRE MANEJO DE PASTAGENS, 20., 2003, Piracicaba. Anais... Piracicaba: FEALQ, 2003. p. 155-186.

EMPRESA BRASILEIRA DE PESQUISA AGROPECUÁRIA - EMBRAPA. Sistema brasileiro de classificação de solos. $2 \mathrm{Ed}$. Rio de Janeiro, 1999. 412 p.

FALLEIRO, R.M.; SOUZA, C.M.; SILVA, C.S.W.; SEDIYAMA, C.S.; SILVA, A.A; FAGUNDES, J.L. Influência dos sistemas de preparo nas propriedades químicas e físicas do solo. Revista Brasileira de Ciência do Solo, v. 27, p. 1097-1104, 2003.

GONÇALVES, A.C.A. Características morfogênicas e padrões de desfolhação em pastos de capim-Marandu submetidos a regimes de lotação contínua. 2002. 124p. Dissertação (Mestrado em Agronomia - Ciência Animal e Pastagens) - Escola Superior de Agricultura Luiz de Queiroz, Piracicaba, SP.

KLUTHCOUSKI, J.; FANCELLI, A.L.; DOURADO-NETO, D.; RIBEIRO, C.M.; FERRARO, L.A. Manejo do solo e o rendimento da soja, milho, feijão e arroz em plantio direto. Scientia

\section{REVENG} 311-319 p. 
Agrícola, Piracicaba, v. 57, n. 1, p. 97-104, 2000.

KÖPPEN, W.; GEIGER, R. Klimate der erde. 1 Ed. Gotha: Verlag Justus Perthes, 1928.

LEITE, M.A.S. Efeitos do preparo do solo e de dois espaçamentos entre fileiras sobre a cultura do milho. 2002. 115 f. Dissertação (Mestrado em Agronomia - Energia na Agricultura) - Faculdade de Ciências Agronômicas, Universidade Federal Paulista, Botucatu, SP. 2002.

MARQUES, J.P. Efeito dos sistemas de manejo do solo e da cobertura de entressafra na cultura da soja. 2002. $233 \mathrm{f}$. Tese (Doutorado em Agronomia - Energia na Agricultura) - Faculdade de Ciências Agronômicas, Universidade Federal Paulista, Botucatu, SP. 2002.

MILLER, D.K. et al. Weed control and cotton tolerance with CGA 362622. In: SOUTHERN WEED SCIENCE SOCIETY, 55., 2002, Atlanta. Proceedings... Atlanta: Hyatt Regency, 2002. p. 30.

MOREIRA FILHO, A.; SILVA, D. S.; ANDRADE, A. P.; PARENTE, H. N.; VIANA, B. L.. Crescimento vegetativo da maniçoba submetida a diferentes manejos de solo, densidade de plantio e alturas e corte. Revista Caatinga, Mossoró, v. 21, n. 4, p. 147-153, 2008.

NASCIMENTO JÚNIOR, D.; DA SILVA, S.C.; ADESE, B. Perspectivas futuras do uso de gramíneas em pastejo. In: REUNIÃO ANUALDASOCIEDADE BRASILEIRA DE ZOOTECNIA, 41.; SIMPÓSIO FORRAGEIRAS E PRODUÇÃO EM PASTAGENS, 2004, Campo Grande. Anais... Campo Grande, MS: EMBRAPA CNPGC, 2004. p. 130-141.

NEIRO, E.S. Propriedades físicas e químicas de um Latossolo Vermelho Distroférrico, sob rotação e sucessão de culturas, sob semeadura direta. 2002. 141p. Dissertação (Mestrado em Agronomia) Universidade Estadual de Maringá, Maringá, PR. 2002.

PEQUENO, D.N.L. Efeito da época de semeadura da Brachiaria brizantha Brizantha em consorcio com milho, sobre caracteres agronômicos da cultura anual e da forrageira em Gurupi, Tocantins. Amazônia:
Ci. \& Desenvolv., Belém, v. 2, n. 3, 2006.

SANTOS, M.L.; CARVALHO, M.P.; RAPASSI, R.M.A.; MURAISHI, C.T.; MALLER, A.; MATOS, F.A. Correlação linear e espacial entre produtividade de milho (Zea mays L.) e atributos físicos de um latossolo vermelho distroférrico sob plantio direto do cerrado brasileiro. Acta Sci., Maringá, v. 28, n. 3, p. 313-321, 2006.

SAS INSTITUTE. SAS user's guide: statistics, version 9.1. Cary, 2002.

SILVA, J.G. Ordens de gradagem e sistemas de aração do solo: desempenho operacional, alterações na camada mobilizada e respostas do feijoeiro (Phaseolus vulgaris L.). 1992. 180 f. Tese (Doutorado Energia na Agricultura) Universidade do Estado de São Paulo, Botucatu, SP. 1992.

SILVA, P.R.A. Mecanismos sulcadores de semeadura-adubadora na cultura do milho no sistema de plantio direto. 2003. 90 f. Dissertação (Mestrado em Agronomia - Energia na Agricultura) - Faculdade de Ciências Agronômicas, Universidade Federal Paulista, Botucatu, SP. 2003.

SUZUKI, L.E.A.S.; ALVES, M.C. Produtividade do milho (Zea mays L.) influenciada pelo preparo do solo e por plantas de cobertura em um latossolo vermelho. Acta Scientiarum. Agronomy, Maringá, v. 26, n. 1, p. 61-65, 2004.

UNIVERSIDADE FEDERAL DE VIÇOSA UFV. SAEG: sistema para análises estatísticas, versão 9.1. Viçosa, 2007.

VALÊNCIA, E.; RODRIGUEZ, A.; ALMODOVAR, L. Tillage effects on botanical composition of bluepea (Clitoria ternatea) guineagrass (Panicum maximum Jacq.) pastures. In: 2008 JOINT ANNUAL MEETING, 2008, Houston. Proceedings... Houston, 2008.

WELLES, J.M.; NORMAN, J.M. Instrument for indirect measurement of canopy architecture. Agronomy Journal, Madisson, v.83, n.5, p.818825, 1991. 